\title{
Polyclonal free light chains: promising new biomarkers in inflammatory disease
}

This article was published in the following Dove Press journal:

Current Biomarker Findings

24 October 2014

Number of times this article has been viewed

Judith A Hampson'

Alice M Turner'

Robert A Stockley ${ }^{2}$

'Department of Clinical and Experimental Medicine, University of Birmingham, ${ }^{2}$ ADAPT (Antitrypsin Deficiency Assessment and

Programme for Treatment), Lung Function and Sleep Department, Queen Elizabeth Hospital, Birmingham, UK
Correspondence: Judith A Hampson ADAPT, Lung Function and Sleep Department, Queen Elizabeth Hospital, Mindelsohn Way, Birmingham BI5 2WB, UK Tel +44 I2I 37I 3886

Email j.a.hampson@bham.ac.uk
Abstract: In this review, we explore potential novel roles of polyclonal free light chains (FLCs) as a biomarker of disease processes and predictor of mortality in different patient populations. In recent years, there have been many publications demonstrating raised polyclonal FLCs in several inflammatory and infective diseases. However, the potential utility of FLCs as a clinical biomarker remains an area of debate. We review the current evidence, and establish whether certain key criteria to fulfill the role of a useful biomarker have been satisfied. In addition, we also consider the potential role of FLCs in the pathophysiology of inflammatory disease and address the concepts of FLCs as both a therapeutic target and potential therapeutic agent.

Keywords: biomarker, free light chains, autoimmune disease, inflammation

\section{Introduction}

A biomarker is defined by the National Institutes of Health working group as "a characteristic that is objectively measured and evaluated as an indicator of normal biological processes, pathogenic processes, or pharmacologic responses to a therapeutic intervention". ${ }^{1}$ One of the main drives behind establishing validated biomarkers is their utility as surrogate end points in clinical trials. Following the observation of increased polyclonal free light chains (FLCs) in a number of autoimmune and inflammatory diseases, many groups have published on their potential role as a biomarker of B-cell activity and adaptive immune activation. In this review article, we explore the utility of polyclonal FLC measurement as a clinical biomarker, examining the available evidence. In addition, we address the known biological properties of FLCs, and discuss their potential role in the pathogenesis of inflammatory disease.

\section{FLC structure}

Within the human body each day, there is an excess of FLCs produced as a byproduct of immunoglobulin synthesis. Immunoglobulins are composed of two heavy chains and two light chains linked by noncovalent forces and disulfide bonds. ${ }^{2}$ There are two light chain isotypes $-\kappa$ and $\lambda$ - and each immunoglobulin molecule contains only one of these isotypes.

\section{Monoclonal versus polyclonal FLCs}

FLCs produced by multiple B-cell clones are termed "polyclonal", whereas Bence Jones proteins (BJPs) are "monoclonal" FLCs produced by a malignant proliferation of a single clone of B cells. Much of the understanding of the structure and immunological 
properties of light chains originally came from the study of BJPs, as they could be readily isolated from both serum and urine specimens for analysis. ${ }^{3}$

\section{FLC structure variability}

Light chains are polypeptides containing both a variable and a constant region. The amino acid sequence of the variable region of light chains is unique to each FLC, and the number of amino acid residues in this region can differ. ${ }^{2}$ The complementary determining residues within the variable region of light chains contribute to the diversity and heterogeneity of FLCs. This is likely to at least in part be responsible for their differing capacity to aggregate and their varying pathogenic potential. $^{4}$

"Free" light chains (ie, those not bound to heavy chains within an immunoglobulin molecule) can exist in monomeric, dimeric, or higher oligomeric and polymeric forms..$^{2,4-7}$ $\kappa$ FLCs are described as generally monomeric in form, but can exist as a noncovalently linked dimer. On the contrary, $\lambda$ FLCs are usually dimeric in form with covalent bonds between them (Figure 1). ${ }^{2}$

\section{FLC synthesis}

Excess FLCs secreted into the circulation are not produced by immunoglobulin breakdown, ${ }^{8}$ but are synthesized de novo by $\mathrm{B}$ cells that are matured beyond the pre-B-cell phase. ${ }^{9}$ Immunoglobulins are produced by polyribosomes within the endoplasmic reticulum, which is where the synthesis of both heavy chains and light chains occurs. ${ }^{10}$ Interestingly, there is a conformational difference between the polypeptides of light chains that are newly synthesized compared to those secreted. The former "precursor" light chain has up to 20 additional amino-terminal residues. ${ }^{11,12}$ These extra residues are cleaved prior to secretion of the FLC. Initially thought to be an unimportant byproduct, the immunological properties of these secreted light chains is now an area of much interest.

\section{Production of polyclonal FLCs in inflammation}

As FLCs are produced as an excess byproduct of antibody production by B cells, measuring FLCs has been proposed to be a biomarker of B-cell activity in a number of autoimmune and
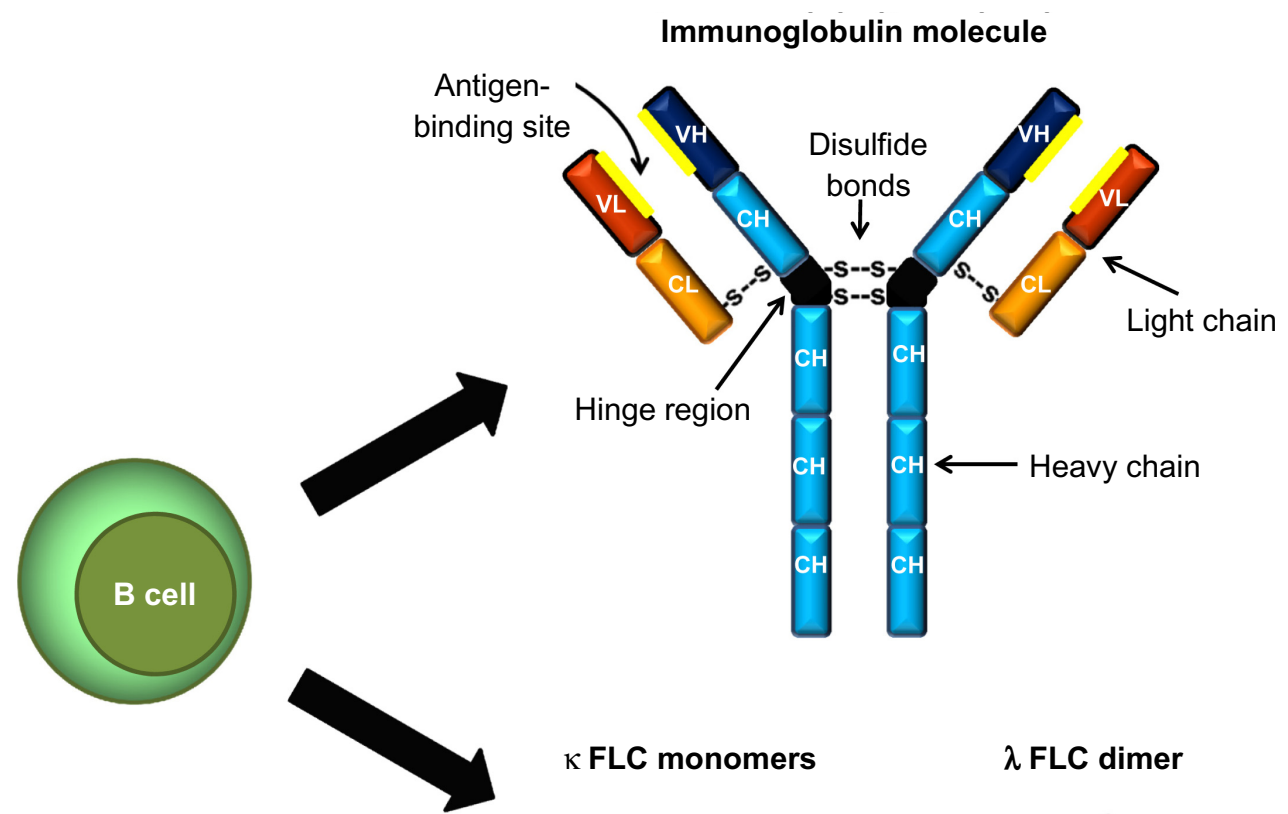

$\kappa$ FLC monomers

$\lambda$ FLC dimer
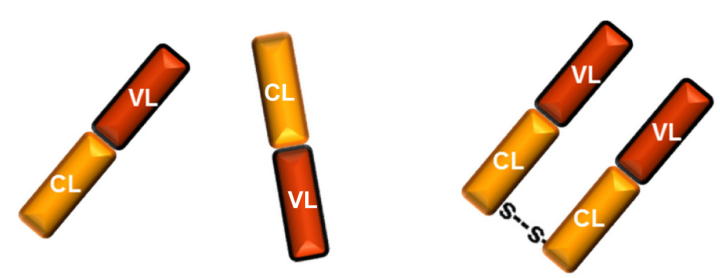

Figure I Immunoglobulin and free light chain (FLC) structure. Immunoglobulins are composed of two heavy chains and two light chains linked by noncovalent forces and disulfide bonds. There are two isotypes of FLC $-\kappa$ and $\lambda$ - which are produced by B cells as a byproduct of immunoglobulin synthesis.

Abbreviations: $\mathrm{V}$, variable region; $\mathrm{C}$, constant region; $\mathrm{H}$, heavy chain; L, light chain. 
inflammatory conditions. In a review by Wahren-Herlenius and Dörner, they describe how "B cell differentiation and activation thresholds are disturbed, leading to skewing of the B cell pool and immunoglobulin production" in systemic autoimmune disease. ${ }^{13}$ Systemic lupus erythematosus (SLE) is an example of an autoimmune disease characterized by production of multiple autoantibodies and hypergammaglobulinemia. ${ }^{13}$ It seems plausible that the excess FLCs produced during this humoral B-cell response explain the increase in polyclonal FLCs seen in the disease state. However, an increase in circulating FLCs has also been observed in inflammatory conditions that are not typically associated with autoantibody production, such as asthma and idiopathic pulmonary fibrosis. ${ }^{14,15}$ This is presumed to be due to polyclonal B-cell activation. An increase in FLCs in response to certain viral infections has also been observed. ${ }^{16,17}$

\section{Measuring FLC concentrations}

The eponymous BJP was first described in $1847 .{ }^{18}$ Historically, serum and urine protein electrophoresis and immunofixation electrophoresis have been employed to quantify monoclonal FLC overproduction and diagnose a number of hematological conditions, including monoclonal gammopathy of undetermined significance, multiple myeloma, primary systemic amyloidosis, and light-chain deposition disease. More recently, an automated immunoassay was developed that could quantify both $\kappa$ and $\lambda$ FLCs with high sensitivity and specificity in the serum. ${ }^{19}$ The assay works by utilizing antibodies that bind to epitopes on the FLCs, which are concealed by the interface between the heavy chain and the light chain in an intact immunoglobulin molecule. The use of this serum FLC assay has been incorporated into many hematological guidelines, negating the need for urine electrophoresis in the screening of many hematological disorders. ${ }^{20}$

The quantity of circulating FLCs depends on the balance between synthesis by B cells and clearance within the kidney. A number of factors can affect the production of FLCs, some of which we have already discussed, such as polyclonal B-cell activation in autoimmune and inflammatory conditions. However, in this situation, the $\kappa / \lambda$ ratio should remain within the normal range. In patients with monoclonal gammopathies, a monoclonal FLC overproduction will alter the balance between $\kappa$ and $\lambda$ FLC production, resulting in an abnormal ratio. ${ }^{20}$ Immune suppression by either a disease process or as a result of drug therapy can cause a reduction in FLC production. Serum FLCs have a half-life of 2-6 hours. They are both excreted and catabolized by the kidney, so impairment in renal function will result in higher circulating FLC concentrations, but the $\kappa / \lambda$ ratio should remain unaltered. ${ }^{21,22}$

Katzmann et al established the normal ranges for serum $\kappa$ and $\lambda$ FLCs using the automated immunoassay, which are as follows: $\kappa, 3.3-19.4 \mathrm{mg} / \mathrm{L} ; \lambda, 5.7-26.3 \mathrm{mg} / \mathrm{L}$; and $\kappa / \lambda$ ratio, $0.26-1.65 .^{23}$

\section{Polyclonal FLCs as biomarkers in disease states: indication of prognosis and outcome Inflammatory and autoimmune diseases}

Interest in polyclonal FLCs as a biomarker started with the observation of increased concentrations in a variety of biological fluids, including blood, synovial fluid, cerebrospinal fluid (CSF), and bronchoalveolar lavage, in patients suffering from different inflammatory and autoimmune conditions. Table 1, while not exhaustive, summarizes the key findings in some of these reports.

There is a need for biomarkers to help identify patients at risk of disease flares, monitor response to treatment, and be a guide to escalating management with immunosuppressive treatments with the aim of limiting end-organ damage. However, to be a truly useful clinical biomarker, there are certain criteria that need to be addressed. Ideally, a biomarker should be central to the pathophysiology of the disease process, relate to disease activity and severity, be stable and fluctuate only with disease flares, predict disease progression, and be sensitive to treatments known to be effective. ${ }^{50}$ Following on from the discovery of increased FLCs in a number of inflammatory conditions, studies have been published examining serum polyclonal FLCs as a marker of disease activity and severity and predictor of outcome, as summarized in Table 2. The greatest number of biomarker-validation criteria has been satisfied in SLE. However, despite this, FLCs are still not currently used in routine clinical practice.

\section{Malignancy}

The prognostic value of measuring monoclonal FLCs in plasma-cell dyscrasias is well documented, but there is increasing interest in polyclonal FLCs as a biomarker in lymphoid malignancies. A polyclonal increase in FLC levels has been found to be a predictor of non-Hodgkin's lymphoma (NHL) in patients with human immunodeficiency virus (HIV). ${ }^{65}$ Abnormal B-cell function is a well-recognized complication of HIV ${ }^{66}$ and Landgren et al wanted to test the hypothesis that the risk of NHL in patients with HIV was 
Table I Summary of some of the key findings of reports regarding increased free light chains (FLCs) measured in biological fluids in the listed autoimmune and inflammatory diseases

\begin{tabular}{|c|c|}
\hline Disease & FLC observations \\
\hline \multirow[t]{6}{*}{ Systemic lupus erythematosus } & Epstein and Tan - Increased FLCs in serum ${ }^{24}$ \\
\hline & Cooper and Bluestone - Increased FLCs in serum, urine, and synovial fluid ${ }^{25}$ \\
\hline & Hirohata and Miyamoto - Increased FLCs in CSF of four of 15 patients with CNS involvement ${ }^{26}$ \\
\hline & Tsai et al - Increased FLCs in urine in patients with active lupus nephritis ${ }^{27}$ \\
\hline & Hopper et al - Increased FLCs in urine during disease activity ${ }^{28}$ \\
\hline & Aggarwal et al - Increased FLCs in serum ${ }^{29}$ \\
\hline \multirow[t]{6}{*}{ Rheumatoid arthritis } & Cooper and Bluestone - Increased FLCs in urine, synovial fluid, and pleural and pericardial effusions ${ }^{25}$ \\
\hline & Sølling et al - Increased FLCs in serum ${ }^{30}$ \\
\hline & Gottenberg et al - Increased FLCs in serum ${ }^{31}$ \\
\hline & Gottenberg et al - Increased FLCs in serum ${ }^{32}$ \\
\hline & Groot Kormelink et al - Increased FLCs in serum and synovial fluid ${ }^{33}$ \\
\hline & Ye et al - Increased FLCs in serum ${ }^{34}$ \\
\hline \multirow[t]{2}{*}{ Sjögren's syndrome } & Moutsopoulos et al - Increased $\lambda$ FLCs in serum ${ }^{35}$ \\
\hline & Gottenberg et al - Increased FLCs in serum ${ }^{31}$ \\
\hline Sarcoidosis & Solling et al - Increased FLCs in serum ${ }^{30}$ \\
\hline Asthma & Kraneveld et al - Increased $\kappa$ FLC levels in serum ${ }^{15}$ \\
\hline COPD & Braber et al - Increased FLCs in serum ${ }^{36}$ \\
\hline Idiopathic pulmonary fibrosis & Groot Kormelink et al - Increased FLCs in serum and bronchoalveolar lavage fluid ${ }^{14}$ \\
\hline Hypersensitivity pneumonitis & Groot Kormelink et al - Increased FLCs in serum and bronchoalveolar lavage fluid ${ }^{14}$ \\
\hline \multirow[t]{4}{*}{ Rhinitis } & $\begin{array}{l}\text { Powe et al - Increased FLCs in nasal secretions in allergic rhinitis (AR) and nasal secretions and serum } \\
\text { in non-AR (NAR) }{ }^{37}\end{array}$ \\
\hline & Groot Kormelink et al - Increased FLCs in serum and nasal secretions (more prominent in patients \\
\hline & with nasal polyposis) ${ }^{38}$ \\
\hline & Meng et al - Increased FLCs in serum and nasal secretions in AR and NAR ${ }^{39}$ \\
\hline \multirow[t]{2}{*}{ Atopic dermatitis } & Kayserova et al - Increased FLCs in serum ${ }^{40}$ \\
\hline & Schouten et al - Increased $\kappa$ FLC levels in serum ${ }^{41}$ \\
\hline Food allergy (cow's milk proteins) & Schouten et al - Increased FLCs in serum ${ }^{41}$ \\
\hline Inflammatory bowel disease & Rijnierse et al - Increased FLCs in serum ${ }^{42}$ \\
\hline \multirow[t]{8}{*}{ Multiple sclerosis } & Rudick et al - Increased FLCs in $\mathrm{CSF}^{43}$ \\
\hline & DeCarli et al - Increased $\kappa$ FLCs and increased $\kappa / \lambda$ ratio in $\mathrm{CSF}^{44}$ \\
\hline & Fagnart et al - Increased FLCs in CSF, increased $\mathrm{KCl}$ ( $\kappa$ chain index $=\kappa$ CSF:serum ratio) \\
\hline & and $\operatorname{LCl}(\lambda \text { chain index })^{45}$ \\
\hline & Krakauer et al - Increased FLCs in $\mathrm{CSF}^{46}$ \\
\hline & Presslauer et al - Increased FLCs in CSF and increased $\mathrm{KCl}^{47}$ \\
\hline & Dobson et al - Increased FLCs in urine ${ }^{48}$ \\
\hline & Senel et al - Increased $\kappa$ FLCs in CSF and increased $\mathrm{KCl}^{49}$ \\
\hline
\end{tabular}

Abbreviations: CSF, cerebrospinal fluid; CNS, central nervous system; COPD, chronic obstructive pulmonary disease.

due to this altered immunoregulatory state ${ }^{65}$ The study found that the NHL risk increased proportionally with increasing FLC levels. An abnormal $\kappa / \lambda$ ratio did not predict NHL in these patients. Interestingly, increased polyclonal FLCs have been observed in many autoimmune conditions that are also associated with an increased risk of NHL, such as rheumatoid arthritis, Sjögren's syndrome, and SLE ${ }^{67}$ Sjögren's syndrome in particular is considered a spectrum of autoimmune disease and lymphoproliferation thought to evolve from polyclonal to overt monoclonal B-cell malignancies. ${ }^{35}$ In one study, $22 \%$ of patients with Sjögren's syndrome were found to have monoclonal gammopathy of undetermined significance, which was associated with a poor clinical outcome. ${ }^{68}$ The detection of monoclonal FLCs in the urine of patients with Sjögren's syndrome has been found to be a potential aid in the diagnosis of lymphoma ${ }^{69}$ However, the utility of measuring polyclonal serum FLCs in predicting the risk of lymphoid malignancies in these conditions has not been evaluated to date. Increased polyclonal FLCs have however been associated with a poor outcome in chronic lymphocytic leukemia, ${ }^{70,71}$ Hodgkin's lymphoma ${ }^{72}$ and diffuse large B-cell lymphoma. ${ }^{73}$

\section{FLCs and infection}

The primary function of the adaptive immune system is to provide an immunological memory to maximize the body's ability to recognize and destroy pathogens capable of causing infection. It is unsurprising, therefore, that as a potential biomarker of "adaptive immune activation", polyclonal 
Table 2 Validation criteria $(\checkmark)$ that have been demonstrated with respect to the different diseases listed; references provided in parentheses

\begin{tabular}{|c|c|c|c|c|c|}
\hline \multirow{2}{*}{$\begin{array}{l}\text { Chronic autoimmune } \\
\text { or inflammatory } \\
\text { disease }\end{array}$} & \multicolumn{5}{|c|}{ FLC biomarker-validation criteria } \\
\hline & $\begin{array}{l}\text { Central to the } \\
\text { pathophysiological } \\
\text { process* }\end{array}$ & $\begin{array}{l}\text { Relates } \\
\text { to disease } \\
\text { activity/severity }\end{array}$ & $\begin{array}{l}\text { Is stable and only } \\
\text { varies with events } \\
\text { known to relate to } \\
\text { disease progression }\end{array}$ & $\begin{array}{l}\text { Predicts } \\
\text { progression }\end{array}$ & $\begin{array}{l}\text { Is sensitive to } \\
\text { intervention factors } \\
\text { that are known } \\
\text { to be effective }\end{array}$ \\
\hline $\begin{array}{l}\text { Systemic lupus } \\
\text { erythematosus }\end{array}$ & $\checkmark(5 \mathrm{I})$ & $\checkmark(27-29,52,53)$ & $\checkmark(28,54)$ & & $\checkmark(52,55)$ \\
\hline Rheumatoid arthritis & $\checkmark(56)$ & $\checkmark(30-34)$ & & & $\checkmark(33)$ \\
\hline Sjögren’s syndrome & $\checkmark(57)$ & $\checkmark(3 \mathrm{I}, 58)$ & & & \\
\hline Sarcoidosis & $\checkmark(59)$ & $\checkmark(30)$ & & & \\
\hline Rhinitis & & & & & $\checkmark(38)$ \\
\hline Atopic dermatitis & & $\checkmark(40)$ & & & \\
\hline Multiple sclerosis & $\checkmark(60)$ & $\checkmark(6 I)$ & & $\checkmark(49,62-64)$ & \\
\hline
\end{tabular}

Note: *The first criterion has been considered to be satisfied if a B-cell response is a key factor in the pathogenesis of the disease. Abbreviation: FLC, free light chain.

increase in FLCs has been seen in a number of different infections. ${ }^{28,30,53}$ Hopper et al observed an increase in urinary FLC measurements in eight inpatients treated for sepsis and pneumonia, which decreased in response to treatment. ${ }^{28}$ This is an important observation to make, as when exploring the utility of FLCs as a biomarker in autoimmune disease, it must be remembered that the patients are at greater risk of infections as a result of both the disease process and often immunosuppressive treatments. It may therefore be difficult to establish if a polyclonal increase in FLCs is solely due to autoimmune/inflammatory disease activity or concurrent infection. If FLCs were utilized clinically, the wrong interpretation of results could cause inappropriate treatment strategies to be undertaken, ie, immunosuppressive therapy given during infection or unnecessary antibiotics to be given during a noninfective disease flare. This was highlighted in a study that examined urinary FLC levels in SLE patients with and without infection, as well as patients with infection without SLE. Neither $\kappa$ nor $\lambda$ FLC measurement was able to distinguish between infection and disease activity. In addition, the patients with active infection without SLE had FLC levels comparable to those seen in SLE patients with a disease flare. ${ }^{53}$

\section{FLCs and human immunodeficiency virus}

High polyclonal FLC levels have also been seen in HIV infection. ${ }^{16,74}$ An inverse relationship between CD4 count and FLC levels has been found, and a polyclonal increase in FLCs is associated with a fourfold increase risk of developing acquired immunodeficiency syndrome (AIDS). ${ }^{75}$ Prolonged infection with HIV and the continuous replication of the virus drives B-cell dysfunction and activation, resulting in FLC overproduction due to the immune system's ongoing efforts to clear the virus. ${ }^{75}$

HIV, AIDS, and some other central nervous system infections are associated with abnormalities in intrathecal immune responses, which can be accompanied by synthesis of FLCs measurable in the CSF. ${ }^{16,45,76,77}$ Contini et al found increased Toxoplasma gondii-specific $\kappa$ FLCs in AIDS patients with $T$. gondii encephalitis compared to both AIDS patients without $T$. gondii encephalitis and controls. ${ }^{78}$ As discussed later, FLCs may also have a protective role in some viral infections. ${ }^{17}$

\section{Mortality}

Polyclonal FLC overproduction has been shown to be associated with an increased risk of mortality. Dispenzieri et al followed up over 15,000 individuals aged 50 years or over who had undergone FLC analysis, and recorded their mortality and cause of death. All of the patients included in the study had a normal $\kappa / \lambda$ ratio, thereby excluding any underlying monoclonal gammopathies. After correcting for age, sex, and renal function they found that a combined FLC level of greater than $47.2 \mathrm{mg} / \mathrm{L}$ was associated with a 2.07 hazard ratio (HR) for death. ${ }^{79}$ These results were echoed in a subsequent study, where combined FLC results above a higher cutoff point of $65 \mathrm{mg} / \mathrm{L}$ were associated with a high risk of death within 100 days (HR 7.1, $P=0.015) .{ }^{80}$ Forty-one percent of the deaths during this period of the study were due to cardiovascular causes. Interestingly, Bellary et al subsequently found a polyclonal increase of FLCs to be a risk factor for cardiovascular events in a cohort of patients with type 2 diabetes. ${ }^{81}$ 
Two studies have looked at the role of polyclonal FLC concentrations in predicting mortality in patients with chronic kidney disease (CKD). The first study, by Haynes et al of 364 patients with stage 3-5 CKD, found that after adjusting for renal function (as measured by estimated glomerular filtration rate) and markers of cardiac damage, only $\lambda$ FLC levels were associated with an increased risk of death. ${ }^{82}$ However, a larger study by Hutchison et al found high FLC levels to be a risk factor for death in a population of 848 patients with $\mathrm{CKD}$ ( $\mathrm{HR} 2.71, P<0.001)$. Multivariate Cox regression analysis demonstrated that the increased risk was independent of renal function. ${ }^{83}$ These studies highlight the potential utility of polyclonal FLCs in risk stratification in both the general population and disease cohorts (Table 3).

\section{Biological properties of FLCs}

Studies of the interaction between FLCs and polymorphonuclear leukocytes were stimulated by the need to understand why patients with renal failure were at increased risk of bacterial infections. Due to their renal clearance, FLCs are increased in the serum of patients with renal failure, and their ability to act as a "uremic toxin" was therefore investigated. Cohen et al demonstrated that polyclonal FLCs isolated from the plasma of patients undergoing hemodialysis inhibited the apoptosis of neutrophils in vitro. ${ }^{84}$ Neutrophils are key effector cells in the innate immune response, and apoptosis is essential for the resolution of inflammation; therefore, by inhibiting apoptosis, FLCs could potentially be responsible for perpetuating chronic neutrophilic inflammation. FLCs have also been shown to influence other neutrophil functions (Figure 2). FLCs themselves are not chemotactic, but when added to neutrophils they inhibit the chemotaxis toward $N$-formyl-methionine-leucine-phenylalanine (FMLP; a strong neutrophil chemoattractant). ${ }^{85}$ In addition, Cohen et al showed that FLCs can reduce neutrophil activation in response to FMLP, as measured by a reduction in deoxyglucose uptake. ${ }^{85}$ Paradoxically, Braber et al found that FLCs can bind to neutrophils in vitro and stimulate IL- 8 production, identifying another mechanism by which FLCs could influence inflammation. ${ }^{36}$

Redegeld et al demonstrated that FLCs can elicit haptenspecific hypersensitivity reactions in sensitized mice. ${ }^{86}$ FLCs can bind to mast cells, promoting activation and degranulation. This effect can be inhibited by using the FLC antagonist F991. Tamm-Horsfall protein is a glycoprotein that is synthesized within the kidney and can bind to both $\kappa$ and $\lambda$ FLCs. Utilizing knowledge of the FLC binding site within this glycoprotein, researchers developed F991, a 9-mer peptide sequence of the Tamm-Horsfall protein, to inhibit FLCs interactions with mast cells. ${ }^{86,87}$

Hutchinson et al demonstrated that FLCs bind to a variety of cell membranes. ${ }^{88}$ They did this by incubating biotinylated FLCs with different cells and using streptavidin allophycocyanin to detect bound protein. This confirmed binding to a number of different cell lines, as well as peripheral blood mononuclear cell subtypes. In particular, there was a particularly high binding affinity for monocytes, leading to speculation regarding the role of FLCs in antigen presentation and immune-response initiation. The antigen-binding capacity of FLCs is however controversial,,${ }^{9,89}$ although recently Thio et al demonstrated the ability of FLCs to bind directly to antigens, supporting their potential to initiate antigen-specific cellular responses..$^{90}$

\section{FLC heterogeneity}

It is important to recognize that the variable structure of both monoclonal and polyclonal FLCs may influence an individual FLC's antigen-binding capacity, pathogenic potential, and ability to interact with immune cells. At present, the specific structural features that distinguish pathological and nonpathological FLCs have not been well described. Myatt et al utilized size-exclusion chromatography to analyze a large number of BJPs (monoclonal FLCs), and found that those that aggregated to form high-molecular-weight multimers in vitro were more likely to be nephrotoxic. ${ }^{4}$ This highlights the point that structural differences are likely to

Table 3 Summary of studies examining the risk of mortality associated with a high combined $(\kappa+\lambda)$ FLC level (cFLC); studies only included if patients with abnormal $\kappa / \lambda$ ratio were excluded from multivariate analysis; confidence intervals provided in parentheses where available

\begin{tabular}{llll}
\hline Study participants & cFLC cutoff (mg/L) & $\begin{array}{l}\text { Multivariate analysis hazard } \\
\text { ratio for death (all causes) }\end{array}$ & $\begin{array}{c}\text { Reference } \\
\text { 15,859 people aged }>50 \text { years from general population }\end{array}$ \\
527 patients referred for FLC analysis & $>47.2$ & $2.1(1.9-2.2)$ & 79 \\
848 patients with CKD not receiving renal replacement therapy & I-unit increase on log scale & $2.71(2.0-3.7)$ & 80 \\
\hline
\end{tabular}

Abbreviations: FLC, free light chain; CKD, chronic kidney disease. 


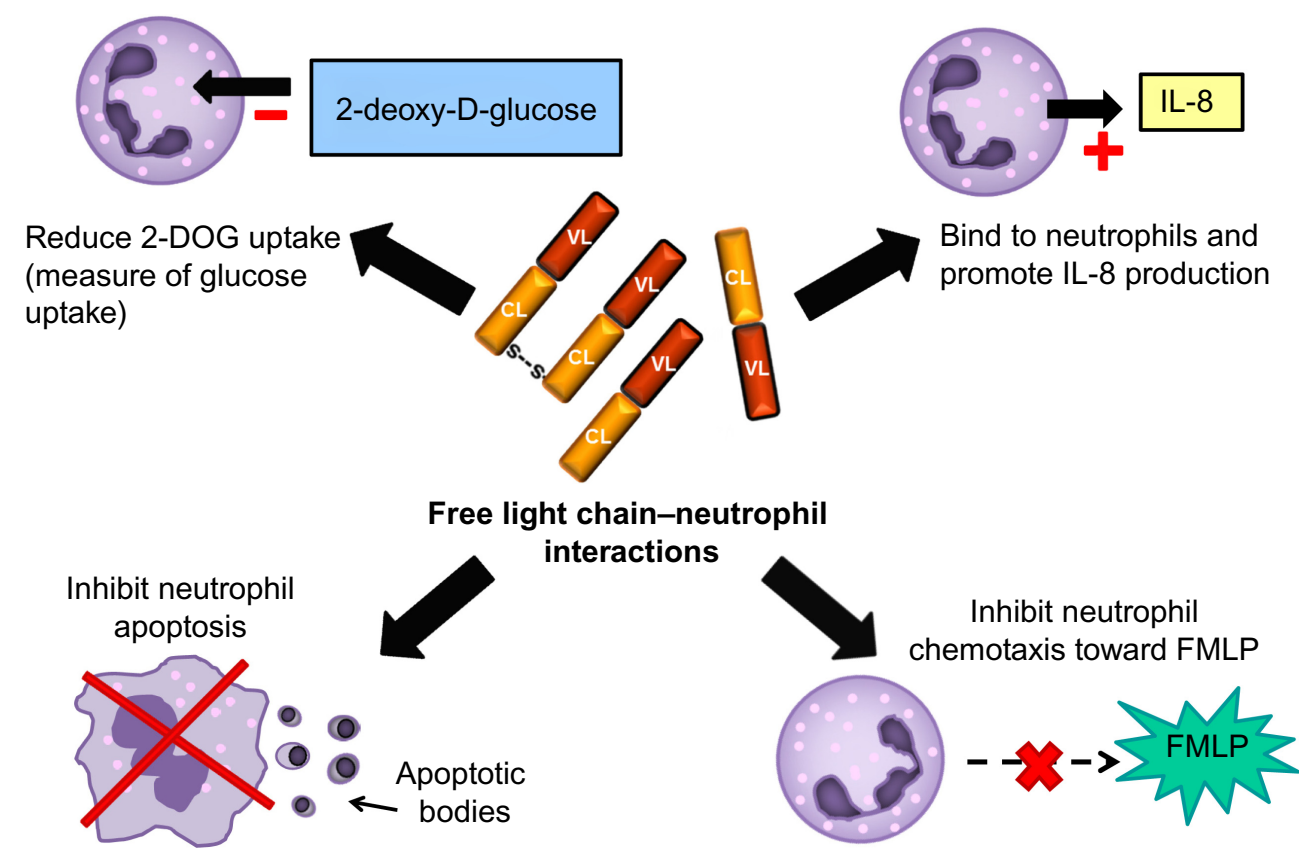

Figure 2 Free light chain (FLC) interactions with neutrophils. In vitro experiments have demonstrated potential interactions between FLCs and neutrophils which are depicted in this diagram.

Abbreviations: V, variable region; C, constant region; L, light chain; FMLP, N-formyl-methionine-leucine-phenylalanine.

impact on the biological properties of FLCs. The source of FLCs (ie, monoclonal versus polyclonal, from urine of myeloma patients, ultrafiltrate from end-stage renal failure patients undergoing dialysis, or synthetically made FLCs) used to perform in vitro and in vivo experiments is therefore of importance when interpreting results. Findings may or may not be translatable to other FLC subtypes. This may explain some of the paradoxical findings reported in the literature to date.

\section{FLCs: potential therapeutic targets or therapeutic agents? \\ FLCs as a therapeutic target}

The biological properties of FLCs have supported the concept of FLCs themselves being pathogenic in inflammatory disease. In recent years, FLCs have become an attractive novel target, with the aim of using antagonists to reduce inflammation and disease activity. This concept remains relatively unexplored, and studies are primarily in animal models and have not been tested in humans.

van Houwelingen et al explored the role of the FLC antagonist F991 as a possible treatment for nonatopic contact-hypersensitivity reactions. Mice were immunized using trinitrophenol-specific FLCs or skin sensitized with dinitrofluorobenzene (DNFB). Following this, they were topically challenged by either picryl chloride or DNFB, respectively. Both methods resulted in ear swelling, which was successfully inhibited by prior application with topical F991 cream. Post-exposure, topical F991 was also able to attenuate symptoms 24 hours after DNFB challenge. ${ }^{91}$ Similarly, Kraneveld et al demonstrated that intranasal treatment with F991 could prevent the development of airway inflammation and obstruction following airway challenge in a murine model of nonatopic asthma. ${ }^{15}$ FLCs could also play a role in the pathogenesis of inflammatory bowel disease through the activation of mast cells. Again using a murine model of skin previously sensitized with DNFB, Rijnierse et al demonstrated that treatment with intraperitoneal F991 prevented cellular infiltration and abrogated the development of diarrhea following rectal challenge with an antigen. ${ }^{42}$

The experiments just described concentrated on the interaction of FLCs and mast cells. However, F991 has also been shown to reduce neutrophil influx in smoke-exposed murine lungs. ${ }^{36}$ In this study, Braber et al treated mice with oropharyngeal F991 twice daily, and demonstrated that the neutrophil count from lung-lavage fluid was reduced compared to untreated smoke-exposed mice. They also showed that F991 can inhibit the binding of FLCs to neutrophils in vitro, suggesting that it acted by impairing the chemotactic response. However, it is important to note that these findings contradict the study by Cohen et al that demonstrated that when added to neutrophils, FLCs impair chemotaxis in vitro. ${ }^{85}$ 


\section{FLCs as a therapeutic agent}

A study by Matsumori et al examining the effects of FLCs in viral myocarditis found that treating encephalomyocarditis virus-inoculated mice with intraperitoneal F991 actually exacerbated the severity of the myocarditis. ${ }^{17}$ FLCs were shown to inhibit encephalomyocarditis viral replication in vitro, and pretreating infected mice with subcutaneous injections of $\kappa$ or $\lambda$ FLCs reduced the size of myocardial lesions and improved survival. To date, this is the only study that has shown a potential therapeutic role for FLCs. There is increasing interest in the pathological effects of FLCs and the potential use of F991 as a treatment in inflammatory disease; however, caution is needed, as this approach could be associated with an increased risk if concomitant infection with certain viruses occurred.

\section{Conclusion and future perspectives}

In this review, we have explored the potential utility of polyclonal FLCs as a biomarker of B-cell activity and adaptive immune activation in a number of autoimmune and inflammatory conditions. The role of B cells in the pathogenesis of many different disease processes does however mean that the clinical utility could be hampered by a lack of specificity. In addition, the adaptive immune response to infections may at times confuse the interpretation of FLC measurements. Further prospective studies are needed to validate the use of FLCs as a biomarker in different disease cohorts. To date, the best evidence supporting their clinical utility is in SLE; however, this has yet to translate into routine clinical practice. FLCs also appear to have a clear role in the diagnosis of multiple sclerosis through CSF FLC analysis, ${ }^{92}$ and may also predict disease progression, although reports even in this indication have been conflicting. ${ }^{49,62-64,92}$

It is important to consider when evaluating a new biomarker whether it has any advantage over other established ones. In inflammation, the relationship between high-sensitivity C-reactive protein CRP (hs-CRP) and FLCs has been evaluated in a study of four chronic disease cohorts and a healthy control population..$^{93}$ Burmeister et al found that there was no correlation between cFLC (combined $\kappa$ and $\lambda$ FLC) levels and hs-CRP within the healthy control group $(r=0.141, P=0.134)$. However, within the chronic disease cohorts (CKD, vasculitis, diabetes, and renal transplant recipients), relatively weak but statistically significant positive correlations were seen. The lack of a strong correlation highlights that
FLCs and CRP are biomarkers of different aspects of the immune system, with CRP reflecting innate immunity and FLCs reflecting adaptive immunity. Although a relationship between the two in chronic inflammatory disease is unsurprising, their individual utilities are thus likely to be different. The possibility of combining these inflammatory markers in mortality-prediction models to gain an overview of the whole immune system has been highlighted in this study as an interesting concept for future research. ${ }^{93}$ From a clinical perspective, if a patient has a polyclonal FLC level above the normal range, the associated increased risk of mortality needs to be recognized by the health care professional involved. Establishing a cause of adaptive immune activation in these individuals and exploring anti-inflammatory therapeutic strategies with the aim of reducing cardiovascular and other risks may be important. There is insufficient evidence at present to prove that interventions that reduce FLC concentrations would positively impact on clinical outcome in these individuals, but it seems a logical approach, and is certainly worthy of further investigation in appropriate prospective trials.

In addition to the potential role of FLCs as a clinical biomarker, understanding the biological functions of FLCs and their role in disease pathophysiology is an important area for further research. Several studies have highlighted the ability of FLCs to interact with mast cells and neutrophils, with the potential of promoting inflammation. Antagonizing FLCs is also a potential novel treatment; however, we need to fully understand all the biological roles of FLCs, and their potential protective or antagonistic role, especially in viral infections, needs to be resolved.

\section{Disclosure}

The authors report no conflicts of interest in this work.

\section{References}

1. Biomarkers Definitions Working Group. Biomarkers and surrogate endpoints: preferred definitions and conceptual framework. Clin Pharmacol Ther. 2001;69(3):89-95.

2. Solomon A. Bence-Jones proteins and light chains of immunoglobulins (first of two parts). N Engl J Med. 1976;294(1):17-23.

3. Solomon A. Light chains of human immunoglobulins. Methods Enzymol. 1985;116:101-121

4. Myatt EA, Westholm FA, Weiss DT, Solomon A, Schiffer M, Stevens FJ. Pathogenic potential of human monoclonal immunoglobulin light chains: relationship of in vitro aggregation to in vivo organ deposition. Proc Natl Acad Sci U S A. 1994;91(8):3034-3038.

5. Abraham RS, Charlesworth MC, Owen BA, et al. Trimolecular complexes of lambda light chain dimers in serum of a patient with multiple myeloma. Clin Chem. 2002;48(10):1805-1811.

6. Berggard I, Peterson PA. Polymeric forms of free normal kappa and lambda chains of human immunoglobulin. J Biol Chem. 1969;244(16): 4299-4307. 
7. Sølling K. Light chain polymerism in normal individuals in patients with severe proteinuria and in normals with inhibited tubular protein reabsorption by lysine. Scand J Clin Lab Invest. 1980;40(2):129-134.

8. Shapiro AL, Scharff MD, Maizel JV, Uhr JW. Synthesis of excess light chains of gamma globulin by rabbit lymph node cells. Nature. 1966;211(5046):243-245.

9. Nakano T, Matsui M, Inoue I, Awata T, Katayama S, Murakoshi T. Free immunoglobulin light chain: its biology and implications in diseases. Clin Chim Acta. 2011;412(11-12):843-849.

10. Askonas BA. Immunoglobulin formation in B lymphoid cells. J Clin Pathol Suppl (Assoc Clin Pathol). 1975;6:8-12.

11. Milstein C, Brownlee GG, Harrison TM, Mathews MB. A possible precursor of immunoglobulin light chains. Nat New Biol. 1972;239(91): $117-120$.

12. Schechter I. Partial amino acid sequence of the precursor of immunoglobulin light chain programmed by messenger RNA in vitro. Science. 1975;188(4184):160-162.

13. Wahren-Herlenius M, Dörner T. Immunopathogenic mechanisms of systemic autoimmune disease. Lancet. 2013;382(9894):819-831.

14. Groot Kormelink T, Pardo A, Knipping K, et al. Immunoglobulin free light chains are increased in hypersensitivity pneumonitis and idiopathic pulmonary fibrosis. PLoS One. 2011;6(9):e25392.

15. Kraneveld AD, Kool M, van Houwelingen AH, et al. Elicitation of allergic asthma by immunoglobulin free light chains. Proc Natl Acad Sci U S A. 2005;102(5):1578-1583.

16. Elovaara I, Seppala I, Kinnunen E, Laaksovirta H. Increased occurrence of free immunoglobulin light chains in cerebrospinal fluid and serum in human immunodeficiency virus-1 infection. J Neuroimmunol. 1991;35(1-3):65-77.

17. Matsumori A, Shimada M, Jie X, Higuchi H, Groot KT, Redegeld FA. Effects of free immunoglobulin light chains on viral myocarditis. Circ Res. 2010;106(9):1533-1540.

18. Jones HB. Papers on chemical pathology, lecture III. Lancet. 1847;II: 88-92.

19. Bradwell AR, Carr-Smith HD, Mead GP, et al. Highly sensitive, automated immunoassay for immunoglobulin free light chains in serum and urine. Clin Chem. 2001;47(4):673-680.

20. Dispenzieri A, Kyle R, Merlini G, et al. International Myeloma Working Group guidelines for serum-free light chain analysis in multiple myeloma and related disorders. Leukemia. 2009;23(2):215-224.

21. Solomon A, Waldmann TA, Fahey JL, McFarlane AS. Metabolism of Bence Jones proteins. J Clin Invest. 1964;43:103-117.

22. Waldmann TA, Strober W, Mogielnicki RP. The renal handling of low molecular weight proteins. II. Disorders of serum protein catabolism in patients with tubular proteinuria, the nephrotic syndrome, or uremia. J Clin Invest. 1972;51(8):2162-2174.

23. Katzmann JA, Clark RJ, Abraham RS, et al. Serum reference intervals and diagnostic ranges for free kappa and free lambda immunoglobulin light chains: relative sensitivity for detection of monoclonal light chains. Clin Chem. 2002;48(9):1437-1444.

24. Epstein WV, Tan M. Increase of L-chain proteins in the sera of patients with systemic lupus erythematosus and the synovial fluids of patients with peripheral rheumatoid arthritis. Arthritis Rheum. 1966;9(5): 713-719.

25. Cooper A, Bluestone R. Free immunoglobulin light chains in connective tissue diseases. Ann Rheum Dis. 1968;27(6):537-543.

26. Hirohata $\mathrm{S}$, Miyamoto T. Increased intrathecal immunoglobulin synthesis of both kappa and lambda types in patients with systemic lupus erythematosus and central nervous system involvement. $J$ Rheumatol. 1986;13(4):715-721.

27. Tsai CY, Wu TH, Sun KH, Lin WM, Yu CL. Increased excretion of soluble interleukin 2 receptors and free light chain immunoglobulins in the urine of patients with active lupus nephritis. Ann Rheum Dis. 1992;51(2):168-172.

28. Hopper JE, Golbus J, Meyer C, Ferrer GA. Urine free light chains in SLE: clonal markers of B-cell activity and potential link to in vivo secreted Ig. J Clin Immunol. 2000;20(2):123-137.
29. Aggarwal R, Sequeira W, Kokebie R, et al. Serum free light chains as biomarkers for systemic lupus erythematosus disease activity. Arthritis Care Res (Hoboken). 2011;63(6):891-898.

30. Sølling K, Sølling J, Rømer FK. Free light chains of immunoglobulins in serum from patients with rheumatoid arthritis, sarcoidosis, chronic infections and pulmonary cancer. Acta Med Scand. 1981;209(6):473-477.

31. Gottenberg JE, Aucouturier F, Goetz J, et al. Serum immunoglobulin free light chain assessment in rheumatoid arthritis and primary Sjögren's syndrome. Ann Rheum Dis. 2007;66(1):23-27.

32. Gottenberg JE, Miceli-Richard C, Ducot B, Goupille P, Combe B, Mariette X. Markers of B-lymphocyte activation are elevated in patients with early rheumatoid arthritis and correlated with disease activity in the ESPOIR cohort. Arthritis Res Ther. 2009;11(4):R114.

33. Groot Kormelink T, Tekstra J, Thurlings RM, et al. Decrease in immunoglobulin free light chains in patients with rheumatoid arthritis upon rituximab (anti-CD20) treatment correlates with decrease in disease activity. Ann Rheum Dis. 2010;69(12):2137-2144.

34. Ye Y, Li SL, Xie M, Jiang P, Liu KG, Li YJ. Judging disease activity in rheumatoid arthritis by serum free kappa and lambda light chain levels. Kaohsiung J Med Sci. 2013;29(10):547-553.

35. Moutsopoulos HM, Steinberg AD, Fauci AS, Lane HC, Papadopoulos NM. High incidence of free monoclonal lambda light chains in the sera of patients with Sjögren's syndrome. J Immunol. 1983;130(6): 2663-2665.

36. Braber S, Thio M, Blokhuis BR, et al. An association between neutrophils and immunoglobulin free light chains in the pathogenesis of chronic obstructive pulmonary disease. Am J Respir Crit Care Med. 2012;185(8):817-824.

37. Powe DG, Groot KT, Sisson M, et al. Evidence for the involvement of free light chain immunoglobulins in allergic and nonallergic rhinitis. J Allergy Clin Immunol. 2010;125(1):139-145.

38. Groot Kormelink T, Calus L, De Ruyck N, et al. Local free light chain expression is increased in chronic rhinosinusitis with nasal polyps. Allergy. 2012;67(9):1165-1172.

39. Meng CD, Dong Z, Sha JC, Li L, Zhu DD. [Analysis of the level and significance of immunoglobulin free light chain in nasal secretion and in serum of patients with allergic rhinitis and non-allergic rhinitis] Zhonghua Er Bi Yan Hou Tou Jing Wai Ke Za Zhi. 2012;47(11): 908-912. Chinese.

40. Kayserova J, Capkova S, Skalicka A, et al. Serum immunoglobulin free light chains in severe forms of atopic dermatitis. Scand J Immunol. 2010;71(4):312-316.

41. Schouten B, van Esch BC, van Thuijl AO, et al. Contribution of IgE and immunoglobulin free light chain in the allergic reaction to cow's milk proteins. J Allergy Clin Immunol. 2010;125(6):1308-1314.

42. Rijnierse A, Redegeld FA, Blokhuis BR, et al. Ig-free light chains play a crucial role in murine mast cell-dependent colitis and are associated with human inflammatory bowel diseases. J Immunol. 2010;185(1):653-659.

43. Rudick RA, Peter DR, Bidlack JM, Knutson DW. Multiple sclerosis: free light chains in cerebrospinal fluid. Neurology. 1985;35(10): 1443-1449.

44. DeCarli C, Menegus MA, Rudick RA. Free light chains in multiple sclerosis and infections of the CNS. Neurology. 1987;37(8): $1334-1338$

45. Fagnart OC, Sindic CJ, Laterre C. Free kappa and lambda light chain levels in the cerebrospinal fluid of patients with multiple sclerosis and other neurological diseases. J Neuroimmunol. 1988;19(1-2):119-132.

46. Krakauer M, Schaldemose Nielsen H, Jensen J, Sellebjerg F. Intrathecal synthesis of free immunoglobulin light chains in multiple sclerosis. Acta Neurol Scand. 1998;98(3):161-165.

47. Presslauer S, Milosavljevic D, Brucke T, Bayer P, Hübl W. Elevated levels of kappa free light chains in CSF support the diagnosis of multiple sclerosis. J Neurol. 2008;255(10):1508-1514.

48. Dobson R, Miller RF, Palmer HE, et al. Increased urinary free immunoglobulin light chain excretion in patients with multiple sclerosis J Neuroimmunol. 2010;220(1-2):99-103. 
49. Senel M, Tumani H, Lauda F, et al. Cerebrospinal fluid immunoglobulin kappa light chain in clinically isolated syndrome and multiple sclerosis. PLoS One. 2014;9(4):e88680.

50. Stockley RA. Biomarkers in COPD: time for a deep breath. Thorax. 2007;62(8):657-660.

51. Fauci AS, Moutsopoulos HM. Polyclonally triggered B cells in the peripheral blood and bone marrow of normal individuals and in patients with systemic lupus erythematosus and primary Sjögren's syndrome. Arthritis Rheum. 1981;24(4):577-583.

52. Hanaoka M, Gono T, Kawaguchi Y, et al. Urinary free light chain is a potential biomarker for ISN/RPS class III/IV lupus nephritis. Rheumatology (Oxford). 2013;52(12):2149-2157.

53. Mastroianni-Kirsztajn G, Nishida SK, Pereira AB. Are urinary levels of free light chains of immunoglobulins useful markers for differentiating between systemic lupus erythematosus and infection? Nephron Clin Pract. 2008;110(4):c258-c263.

54. Hopper JE, Sequeira W, Martellotto J, Papagiannes E, Perna L, Skosey JL. Clinical relapse in systemic lupus erythematosus: correlation with antecedent elevation of urinary free light-chain immunoglobulin. J Clin Immunol. 1989;9(4):338-350.

55. Chiche L, Cournac JM, Mancini J, et al. Normalization of serum-free light chains in patients with systemic lupus erythematosus upon rituximab treatment and correlation with biological disease activity. Clin Rheumatol. 2011;30(5):685-689.

56. Martinez-Gamboa L, Brezinschek HP, Burmester GR, Dörner T. Immunopathologic role of B lymphocytes in rheumatoid arthritis: rationale of B cell-directed therapy. Autoimmun Rev. 2006;5(7):437-442.

57. Tzioufas AG. B-cell lymphoproliferation in primary Sjögren's syndrome. Clin Exp Rheumatol. 1996;14 Suppl 14:S65-S70.

58. Gottenberg JE, Seror R, Miceli-Richard C, et al. Serum levels of $\beta 2$-microglobulin and free light chains of immunoglobulins are associated with systemic disease activity in primary Sjögren's syndrome. Data at enrollment in the prospective ASSESS cohort. PLoS One. 2013;8(5):e59868.

59. Saussine A, Tazi A, Feuillet $S$, et al. Active chronic sarcoidosis is characterized by increased transitional blood B cells, increased IL-10-producing regulatory B cells and high BAFF levels. PLoS One. 2012;7(8):e43588.

60. Owens GP, Bennett JL, Gilden DH, Burgoon MP. The B cell response in multiple sclerosis. Neurol Res. 2006;28(3):236-244.

61. Mehta PD, Cook SD, Troiano RA, Coyle PK. Increased free light chains in the urine from patients with multiple sclerosis. Neurology. 1991;41(4):540-544.

62. Rinker JR 2nd, Trinkaus K, Cross AH. Elevated CSF free kappa light chains correlate with disability prognosis in multiple sclerosis. Neurology. 2006;67(7):1288-1290.

63. Rudick RA, Medendorp SV, Namey M, Boyle S, Fischer J. Multiple sclerosis progression in a natural history study: predictive value of cerebrospinal fluid free kappa light chains. Mult Scler. 1995;1(3): $150-155$.

64. Villar LM, Espiño M, Costa-Frossard L, Muriel A, Jiménez J, Alvarez-Cermeño JC. High levels of cerebrospinal fluid free kappa chains predict conversion to multiple sclerosis. Clin Chim Acta. 2012;413(23-24):1813-1816.

65. Landgren O, Goedert JJ, Rabkin CS, et al. Circulating serum free light chains as predictive markers of AIDS-related lymphoma. J Clin Oncol. 2010;28(5):773-779.

66. Moir S, Buckner CM, Ho J, et al. B cells in early and chronic HIV infection: evidence for preservation of immune function associated with early initiation of antiretroviral therapy. Blood. 2010;116(25):5571-5579.

67. Smedby KE, Hjalgrim H, Askling J, et al. Autoimmune and chronic inflammatory disorders and risk of non-Hodgkin lymphoma by subtype. J Natl Cancer Inst. 2006;98(1):51-60.

68. Brito-Zeron P, Retamozo S, Gandia M, et al. Monoclonal gammopathy related to Sjögren syndrome: a key marker of disease prognosis and outcomes. J Autoimmun. 2012;39(1-2):43-48.
69. Walters MT, Stevenson FK, Herbert A, Cawley MI, Smith JL. Urinary monoclonal free light chains in primary Sjögren's syndrome: an aid to the diagnosis of malignant lymphoma. Ann Rheum Dis. 1986;45(3): 210-219.

70. Maurer MJ, Cerhan JR, Katzmann JA, et al. Monoclonal and polyclonal serum free light chains and clinical outcome in chronic lymphocytic leukemia. Blood. 2011;118(10):2821-2826.

71. Morabito F, De Filippi R, Laurenti L, et al. The cumulative amount of serum-free light chain is a strong prognosticator in chronic lymphocytic leukemia. Blood. 2011;118(24):6353-6361.

72. Thompson CA, Maurer MJ, Cerhan JR, et al. Elevated serum free light chains are associated with inferior event free and overall survival in Hodgkin lymphoma. Am J Hematol. 2011;86(12):998-1000.

73. Maurer MJ, Micallef IN, Cerhan JR, et al. Elevated serum free light chains are associated with event-free and overall survival in two independent cohorts of patients with diffuse large B-cell lymphoma. J Clin Oncol. 2011;29(12):1620-1626.

74. Bibas M, Lorenzini P, Cozzi-Lepri A, et al. Polyclonal serum-free light chains elevation in HIV-infected patients. AIDS. 2012;26(16): 2107-2110.

75. Shiels MS, Landgren O, Costello R, Zingone A, Goedert JJ, Engels EA. Free light chains and the risk of AIDS-defining opportunistic infections in HIV-infected individuals. Clin Infect Dis. 2012;55(10):e103-e108.

76. Gallo P, Piccinno MG, De Rossi A, et al. Free light chains of immunoglobulins in the cerebrospinal fluid of human immunodeficiency virus type 1-infected patients. J Neuroimmunol. 1990;26(3):229-238.

77. Grimaldi LM, Castagna A, Maimone D, et al. Kappa light chain predominance in serum and cerebrospinal fluid from human immunodeficiency virus type 1 (HIV-1)-infected patients. J Neuroimmunol. 1991;32(3):259-268.

78. Contini C, Fainardi E, Cultrera R, et al. Evidence of cerebrospinal fluid free kappa light chains in AIDS patients with Toxoplasma gondii encephalitis. J Neuroimmunol. 2000;108(1-2):221-226.

79. Dispenzieri A, Katzmann JA, Kyle RA, et al. Use of nonclonal serum immunoglobulin free light chains to predict overall survival in the general population. Mayo Clin Proc. 2012;87(6):517-523.

80. Anandram S, Assi LK, Lovatt T, et al. Elevated, combined serum free light chain levels and increased mortality: a 5-year follow-up, UK study. J Clin Pathol. 2012;65(11):1036-1042.

81. Bellary S, Faint JM, Assi LK, et al. Elevated serum free light chains predict cardiovascular events in type 2 diabetes. Diabetes Care. 2014;37(7):2028-2030.

82. Haynes R, Hutchison CA, Emberson J, et al. Serum free light chains and the risk of ESRD and death in CKD. Clin J Am Soc Nephrol. 2011;6(12):2829-2837.

83. Hutchison CA, Burmeister A, Harding SJ, et al. Serum polyclonal immunoglobulin free light chain levels predict mortality in people with chronic kidney disease. Mayo Clin Proc. 2014;89(5):615-622.

84. Cohen G, Rudnicki M, Deicher R, Hörl WH. Immunoglobulin light chains modulate polymorphonuclear leucocyte apoptosis. Eur J Clin Invest. 2003;33(8):669-676.

85. Cohen G, Haag-Weber M, Mai B, Deicher R, Hörl WH. Effect of immunoglobulin light chains from hemodialysis and continuous ambulatory peritoneal dialysis patients on polymorphonuclear leukocyte functions. J Am Soc Nephrol. 1995;6(6):1592-1599.

86. Redegeld FA, van der Heijden MW, Kool M, et al. Immunoglobulinfree light chains elicit immediate hypersensitivity-like responses. Nat Med. 2002;8(7):694-701.

87. Huang ZQ, Sanders PW. Localization of a single binding site for immunoglobulin light chains on human Tamm-Horsfall glycoprotein. J Clin Invest. 1997;99(4):732-736.

88. Hutchinson AT, Jones DR, Raison RL. The ability to interact with cell membranes suggests possible biological roles for free light chain. Immunol Lett. 2012;142(1-2):75-77.

89. Sun M, Li L, Gao QS, Paul S. Antigen recognition by an antibody light chain. J Biol Chem. 1994;269(1):734-738. 
90. Thio M, Groot Kormelink T, Fischer MJ, Blokhuis BR, Nijkamp FP, Redegeld FA. Antigen binding characteristics of immunoglobulin free light chains: crosslinking by antigen is essential to induce allergic inflammation. PLoS One. 2012;7(7):e40986.

91. van Houwelingen AH, Kaczynska K, Kraneveld AD, Kool M, Nijkamp FP, Redegeld FA. Topical application of F991, an immunoglobulin free light chain antagonist, prevents development of contact sensitivity in mice. Clin Exp Allergy. 2007;37(2):270-275.
92. Presslauer S, Milosavljevic D, Huebl W, Parigger S, Schneider-Koch G, Bruecke T. Kappa free light chains: diagnostic and prognostic relevance in MS and CIS. PLoS One. 2014;9(2):e89945.

93. Burmeister A, Assi LK, Ferro CJ, et al. The relationship between highsensitivity CRP and polyclonal free light chains as markers of inflammation in chronic disease. Int J Lab Hematol. 2014;36(4):415-424.

Current Biomarker Findings

\section{Publish your work in this journal}

Current Biomarker Findings is an international, peer-reviewed, open access journal publishing original research, reports, reviews and commentaries on all areas of biomarker research. The manuscript management system is completely online and includes a very quick and fair

\section{Dovepress}

peer-review system. Visit http://www.dovepress.com/testimonials.php to read real quotes from published authors. 